\title{
A STUDY OF THE LESIONS IN A CASE OF TRAUMA OF THE CERVICAL REGION OF THE SPINAL CORD SIMULATING SYRINGO- MYELIA.
}

BY JAMES HENDRIE LLOYD, A.M., M.D.

Neurologist to the Philadelphia Hospital, Philadelphia.

IN 1894 I published a report of two cases of traumatic affections of the cervical region of the spinal cord simulating syringomyelia. ${ }^{1}$ In both of these cases there had been severe injury, involving a fracture of the spine in the cervical region, and evidently a wound to the spinal cord. Both patients had survived for a long term of years after the original accidents, and both presented to a marked degree the clinical aspects of syringomyelia. Thus there was progressive muscular atrophy in the shoulders, arms and hands; spastic paraplegia with exaggerated knee jerks, but withont persisting paralysis of the bladder and rectum; some trophic lesions, and, finally, the peculiar dissociation symptom, i.e., preservation of tactile sense with abolition of sensibility to heat, cold and pain. These cases were regarded at the time as instances possibly of pachymeningitis cervicalis hypertrophica, altbough I distinctly stated that I did not intend to commit myself positively to a statement that they were necessarily or even probably examples of an inflammatory process. They simply conformed to the clinical type of syringomyelia, and I was not satisfied in my mind that they were not degenerative or necrotic rather than inflammatory.

Since the report of these cases one of the patients has died, and the antopsy and microscopic examinations are of such great interest that I desire to embody a report of them in another paper. The case has importance from two standpoints. First, with reference to the etiology of syringo-

' Journal of Montal and Nervous Diseases, June, 1894. 
myelis. Second, with reference to the light which it throws upon sensory conduction in the spinal cord. These subjects will be discussed after a description of the case and the sections.

In reporting the clinical history of the case here I shall abstract briefly the report in the former paper just referred to.

Patrick C., aged 60 years, white, male, labourer, had received when 30 years of age an injury to the cervical and dorsal spine by being jammed between two canal boats in a canal lock. For treatment he said that he was kept strapped to a long dorsal splint or platform for five weeks. He must have made a good recovery, for in about three months he returned to work as a common labourer, and continued to do hard work up to the time when be received a second severe accident. This second accident happened about two years before his admission to the hospital, hence after an interval of nearly thirty years. He was in good hesalth at the time. While digging out a clay bank he was buried under a landalide, where he remained about one half hour before he was rescued. He was unconscious for twenty-four hours. On recovering consciousness it was found that he had paralysis in the left arm and leg. The face was not involved and there was no affection of speech. He remained in the hospital for six months. Contractures gradually began in the affected arm and leg.

His condition when first seen by me, three years after the accident, was as follows:

There was an angular deformity, involving the seventh cervical and first and second dorsel vertebræ, and there was a depression also in the region of the lumbar vertebræ. The deformity caused the patient to carry his head in a set position, his chin almost resting on the thorax (fig. 1). The left arm and leg were paralysed, and there was contracture of the arm and forearm. The shoulder muscles and muscles of the arm were paralysed and atrophied, and there were fibrillary contractions in them. Clonus was marked in the fingers, wrist, and ankle of both sides, and the phenomena of so-called spinal epilepsy were readily obtained in the legs. This general leg clonus once started would continue almost indefinitely.

The sensory symptoms were of great interest. The patient was unable to distinguish heat from cold or to recognise either in the region marked on the chart. It is to be observed that this thermo-anæsthesia was on the right side or the side opposite the 


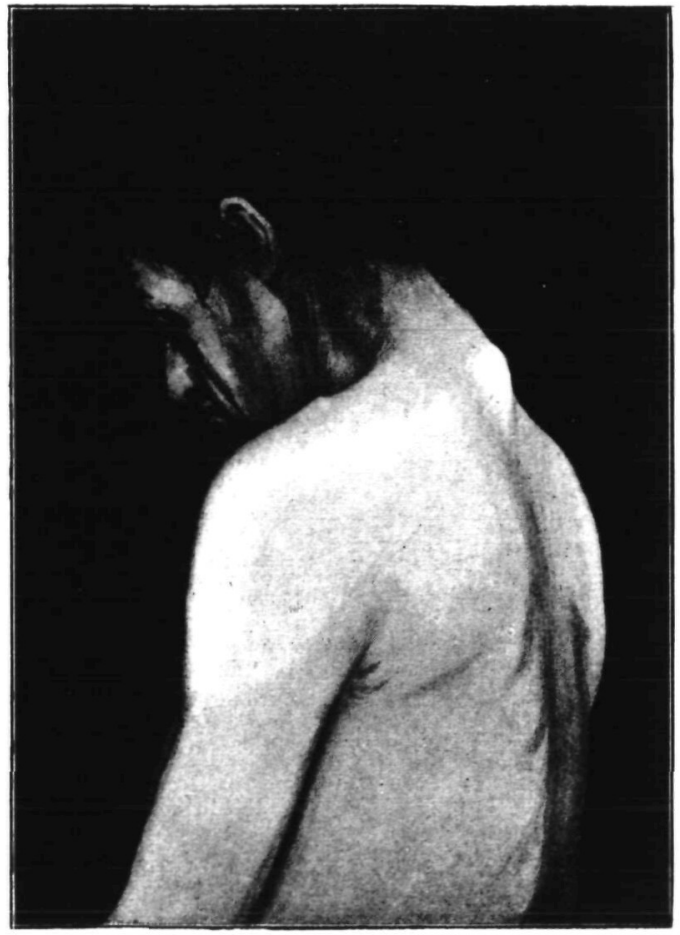

Fig. 1.

A case of trauma of the cervical region of the spinal cord. 

paralysis of motion (figs. 2 and 3). There was one area of anæsthesia on the right leg (fig. 4). There was also a form of hyperæsthesia or rather parøsthesia of the right or unparalysed side. Thus he experienced and complained much of a sensation of burning on this side, and wanted constantly to put cold water on it to allay the heat, but he found this remedy ineffectual.

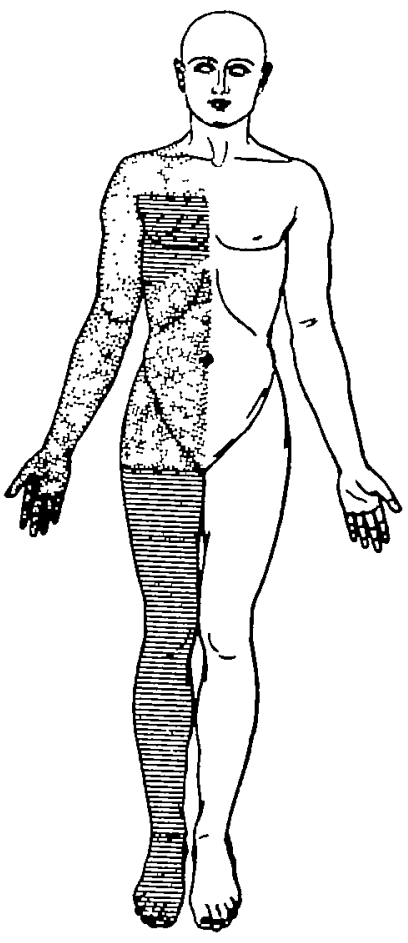

Fia. 2.

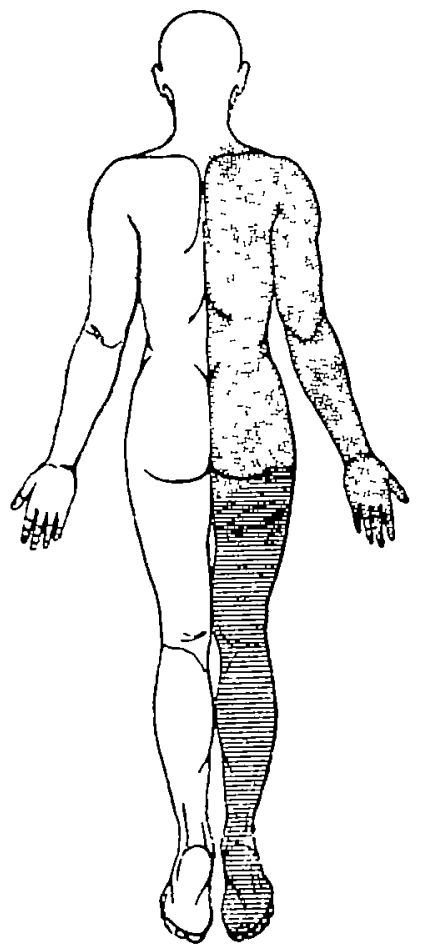

Fig. 9.

Thermo-anesthesis indicated by cross-lines. Ansigesia in the same areas, and also in aress indicated by dotted shading.

Finally, he was profoundly analgesic in the right arm, side and leg. The iris was not involved, nor was there any impairment of respiration or any interference with the innervation of the blodder.

Commenting on this case in the former report I observed that its prominent feature was its hemiplegic type. This 
was so pronounced that the case closely resembled one of cerebral lesion. That it was not such, however, was clear from its history, as well as from the deformity of the spine, the absence of paralysis of the face or tongue, the sensory changes and the atrophy and fibrillation in the paralysed muscles. It is to be observed that it followed closely the

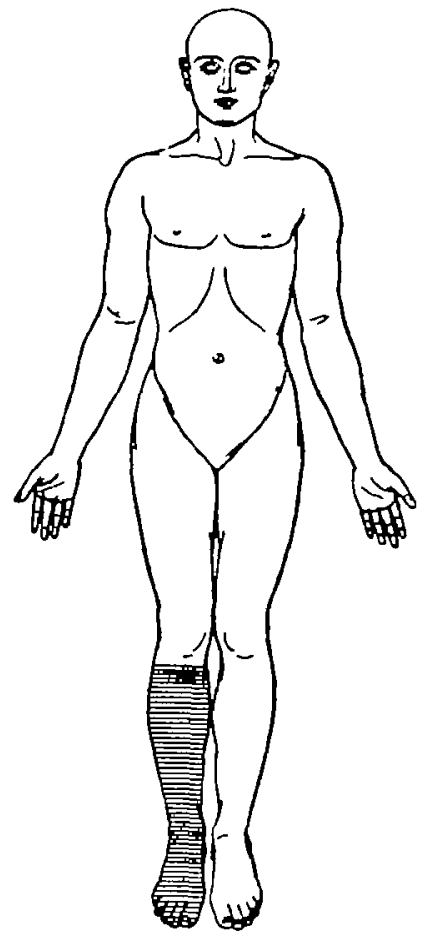

Fro. 4.

Tactile anmsthesis, varied with delayed sensation.

Brown-Sequard type, i.e., the paralysis of motion was on one side and the sensory changes on the other. Its resemblance to syringomyelia was borne out by the peculiar dissociation symptom and the muscular atrophy in the shoulder and arm. As to its hemiplegic type, it must be borne in mind that syringomyelia occasionally presents this 
form. That it was the direct effect of accident was evident from the fact that it supervened immediately on the receipt of the injury from the clay bank, which had evidently resulted in a fracture of one or more of the vertebræ of the lower cervical and upper dorsal spine. It seems certain that the injury was the result of the second accident, because the man had completely recovered from the effect of the first accident thirty years before, so that he had been able to do hard work.

The patient died about one year ago from some intercurrent affection. Thus an interval of about five years had elapsed between the receipt of his second injury and his death.

The findings at the autopsy were as follows:

Before the spinal canal was opened, a deformity of the 3 rd, 4th, and 5th cervical vertebræ was seen. The spinous processes of these vertebræ were gone, and an osseous mass, resembling callus, was seen on either side of the spinal column. The cord was removed quite easily up to the 6 th cervical vertebræ, where the dura was adherent anteriorly to the body of the vertebra, bat was free posteriorly. At the junction of the 4 th and 5 th cervical vertebræ an angular deformity, projecting into the spinal canal, compressed the cord, which was here ribbon-like. The point of greatest compression was at this prominence. The bodies of the 3rd and 4th cervical vertebræ were flattened. Again, at the 2nd and 3rd cervical vertebrø there was an angular projection, caused by a fracture and dislocation of these two vertebræ, with, however, no corresponding deformity in the spinal canal. On the body of the $7 \mathrm{th}$ cervical vertebra there was a sharp projecting point. It seemed to be an exostosis, but there was no other evidence of fracture in this region. The cord was much flattened antero-posteriorly at the exits of the $5 \mathrm{th}, 6 \mathrm{th}$ and $7 \mathrm{th}$ cervical roots. At and above the exit of the 4th cervical roots the cord was little if any deformed. At the exit of the 8 th cervical roots the cord began to assume a normal appearance, and nothing abnormal was noted below this level. The dura at the 3rd and 4th roots was fully twice as thick as normal at the 
posterior part, but anteriorly it was normal. There was no other distinct evidence of meningitis, unless it was at the 5 th, 6th and 7th posterior roots and on the left side only, where the arachnoid was a little more adherent than is usually observed. There was a spiculum of bone attached exactly to the median and lateral parts of the dura at the exit of the 7 th roots, and at this point there was a mass of fibrous tissue possibly resulting from external pachymeningitis. In the brain nothing abnormal was noted.

\section{Microscopic Appearances.}

Seventh Cervical Segment (fig. 5).-This is the level of greatest destruction. The whole cord is flattened or ribbon-like at this point. The left half of the cord is extensively injured. The area of greatest involvement includes the left antero-lateral column (the pyramidal tract, cerebellar tract, and Gowers' tract), the anterior and posterior horns, the anterior portion of the posterior columns, and the gray and the white commissures. The lesion extends across to the right side of the cord along the commissure, but in its greatest intensity stops before reaching the horns of the right side. The right half of the cord, however, shows some diffused degeneration of slight degree in the anterolateral column, and the anterior and posterior horns are misshapen and slightly degenerated. It is interesting to note that the lesion occupies much the same ground as most cases of syringomyelia, also that the posterior columns are affected chiefly in their anterior part, i.e., contiguous to the gray commissure. The left half of the cord in the lateral column is a mass of necrosed tissue, including everything except the extreme anterior column and column of Türck, which are well preserved. The affected area of the posterior columns at this level does not include Schultze's comma zones. It is a somewhat irregular mass of degenerated tissue beginning at the gray commissure anteriorly and extending in a posterior direction so as to include not quite one-third of the columns. In a lateral direction it extends 

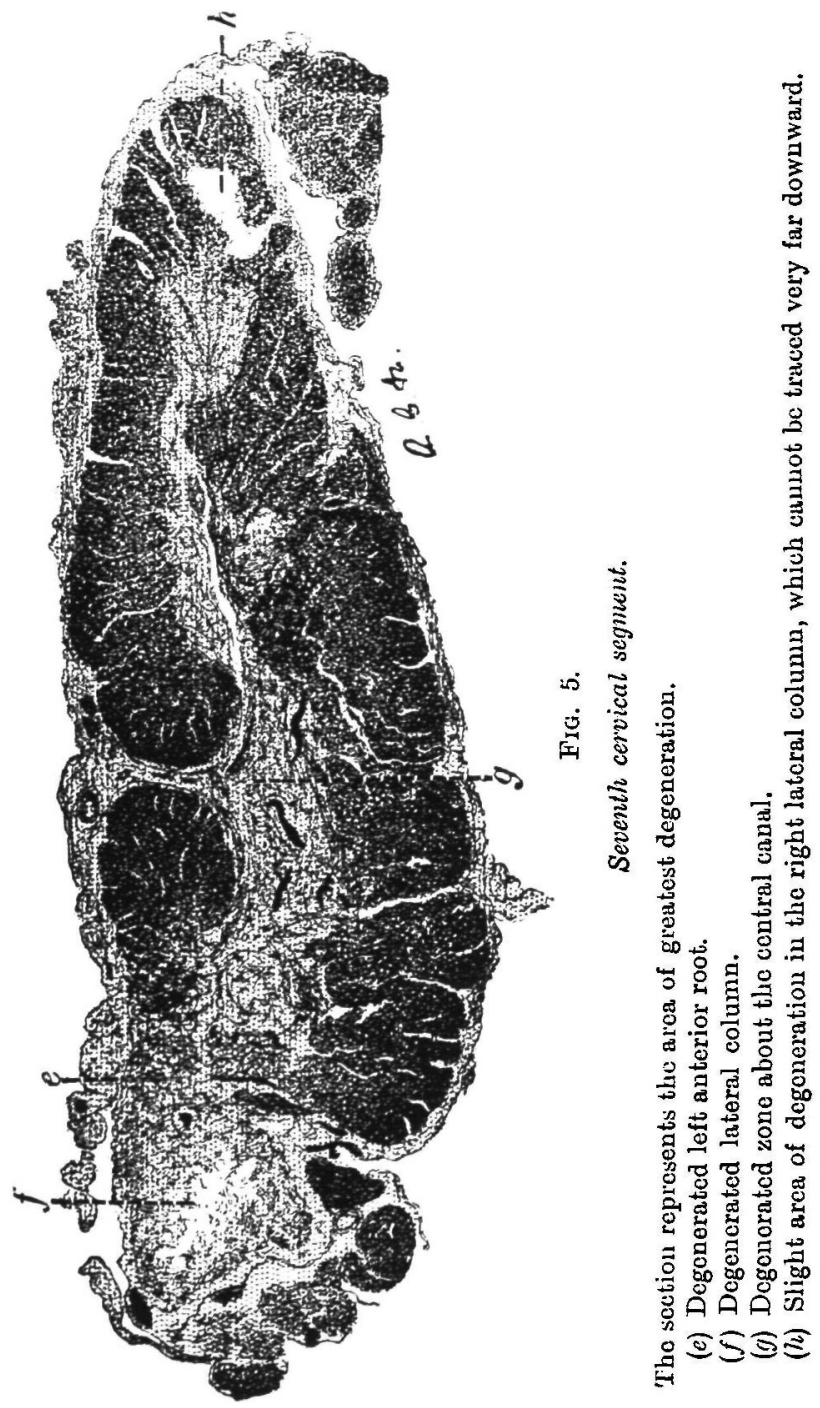
irregularly as far as the posterior horns and is rather more extensive in the left posterior column than in the right. It has no definite outline, and cannot be said to be limited to any special group of fibres. It is, however, the starting place for an ascending degeneration in the posterior columns which at higher levels assumes a peculiar branching or $W$ form which will be referred to later. ${ }^{1}$ It is thus seen that a large portion of the fibres in the posterior columns escape the lesion (and this doubtless accounts for the preservation of tactile sense).

There is no cavity formation in any part of the cord at this level, nor is any cavity found at any other level of the cord. It is to be noted, however, that the position of the lesion is practically identical with what is seen in many cases of syringomyelia. Thus there is a well marked degenerative zone about the central canal involving both the gray and the white commissures, which at this level are quite obliterated. The only degeneration in the posterior column is that which is contiguous to this central zone of necrosed tissue. This extensive degeneration of the central gray matter of the cord must have acted effectually as a bar to the transmission at this level of any impulses through them from one side to the other. Finally, the extensive necrotic area on the left side, involving both the posterior and anterior horn, the pyramidal tract, the direct cerebellar tract, and Gowers' tract, acts almost though not quite as a hemisection of the cord. The only notable fibres to escape are those in the posterior columns and in the anterior columns and columns of Türck.

Starting from this point we may first trace the ascending degeneration through the higher levels of the cord and,

1 Bruce ("On the Endogenous or Intrinsic Fibres in the Lumba-Sacral Cord," Brain, part lxix., 1897), refers to the cornu-commissural tract in the lumbar region, described by Marie as being composed of endogenous fibres. This tract lies in the anterior part of the posterior column in close apposition to the posterior horn, commissure and septum. It does not degenerate in locomotor ataxia, or after injuries to the cauda equina, but degenerates after injuries to the posterior horns, which are supposed to contain its cells of origin. It also degenerates in syringomyelis. This degeneration is said to be descending. It is almost this identical area that has degeneratod in my case, only in this instance the tract is in the corvical regiou, and the degeneration appears to be upward. That these fibres are endogenous is bighly probable. 
second, the descending degeneration below the seat of the lesion.

Sixth Cervical Segment.-At this level the left half of the cord is also much involved. The degenerated area involves the left pyramidal tract, cerebellar tract and Gowers' tract, and the left posterior and anterior horn. The posterior columns are only involved in the region contiguous to the gray commissure. Hence most of the fibres of the posterior columns escape. The left column is rather more involved than the right. It is to be noted that at this level both the grey and white commissures preserve their normal size, shape, and appearance. There is no dilatation or cavity formation.

Fifth Cervical Segment.-The cord here is still misshapen. The left lateral region is smaller and deeply degenerated. The degeneration in the posterior columns still retains the general outline that was seen at the lower level. The anterior horns are normal in shape and size, but possibly have fewer multipolar cells than normal. The right pyramidal tract and direct cerebellar tract are the seat of a very slight diffuse degeneration. This is seen especially in the pyramidal tract.

Third Cervical Segment.-The posterior columns still present some areas of ascending degeneration. These areas have now taken a more definite shape. They are branching streaks of degeneration passing outward or backward from the region of the gray commissure. The great mass of fibres, however, in the posterior columns are normal. On the left side the cord is still slightly deformed, and here the cerebellar tract and Gowers' tract are deeply degenerated and the crossed pyramidal tract is also the seat of diffuse degeneration. (Ascending degeneration of the pyramidal tract). The central region of the cord (posterior gray and anterior white commissure) is normal. The anterior horns uppear at this level to have some degenerated multipolar cells. The right horn especially is smaller than the left, and has not many large cells.

Upper Cervical Cord.-The same general appearances are seen as in the third cervical segment, except that the 
anterior horns at this level are normal and contain many large multipolar cells.

Decussation of the Pyramids.-At this level the posterior columns show very plainly two well defined areas of degeneration forming lines or streaks extending first from neer the grey commissure in a posterior direction through Bardach's column, and second from s point in Goll's column at the posterior longitudinal fissure backward and outward not extending to the border of the cord. Neither of these zones occupies exactly the region of Schultze's comma zone. It is thus seen, as said already, that the posterior columns are not degenerated in their entirety, but that the vast mass of their fibres escape. It is difficult to account for these peculiarly shaped areas of degeneration in the posterior columns. They maintain the same shape through several segments of the cord above the level of injury. The question may be raised whether these areas of degeneration are caused by the arrangement of the fibres coming in at the point of injury, passing gradually inward toward Goll's column as they ascend. It is possible, however, that they are endogenous fibres, originating in the gray matter at the seat of injury. The cerebellar tract and Gowers' tract are deeply degenerated on the left side.

Medulla Oblongata, Decussation of the Lemniscus.-At this point the direct cerebellar tract and Gowers' tract are still deeply degenerated on the left side. On the right side they are normal. The antero-lateral ground bandles are normal. The nucleus gracilis and nucleus cuniati as compared with sections of normal cords are normal. The posterior columns at this level do not appear degenerated, certainly Burdach's column is not. Goll's columns show deeply stained (non-degenerated) rim of medullated fibres around the nuclei gracilis. (This has been carefully compared with selections from a normal medulla with the result that there may be slight evidence of degeneration in Goll's columns; if so, this probably represents the group of degenerated fibres running apward through the posterior columns as observed at lower levels.) At this level some of these fibres have probably already terminated in the nuclei 
gracilis and cuniati. It is thus of interest to note that at this the highest level of the posterior columns their great mass of fibres is not degenerated. There is no evidence of ascending degeneration of the pyramidal tract beyond one or two segments above the seat of injury. This is in marked contrast with what I found in a case of syringomyelia formerly reported, ${ }^{1}$ in which there was deep ascending. degeneration of one of the pyramidal tracts extending through and above the decussation of the pyramids.

\section{Descending Degeneration.}

Eighth Cervical Segment (fig. 6).-This is just below the seat of injury. The cord is slightly contracted in form on the left side. In the posterior columns Schultze's comma zones are plainly degenerated (descending degeneration). There is also slight diffuse degeneration in the posterior colamns which extends only a short distance downward. This is probably caused by the degeneration of the descending branches of the exogenous fibres. It is rather too plainly marked in the illustration. The left lateral pyramidal tract is deeply degenerated, the right only slightly so. The anterior horns contain many multipolar cells some of which are possibly somewhat degenerated. The direct cerebellar tract and Gowers' tract are normal on both sides.

First Dorsal Segment.-The crossed pyramidal tract on the left side is deeply degenerated. This tract on the right side is only slightly degenerated. In the posterior columns Schultze's comma zones are still degenerated. There is also some diffuse degeneration in these columns already referred to (descending branches of exogenous fibres). The anterior horns contain normal multipolar cells.

Second Dorsal Segment. - Deep degeneration of the left lateral pyramidal tract. The slight degeneration in the posterior columns is not so marked as in the preceding section. Schultze's comma zones are not so distinct. Horns normal. From this level downward the cord presents simply deep degeneration in the left lateral pyramidal tract. The posterior columns soon become normal in their entire extent.

1 University Medical Magazine, March, 1893. 


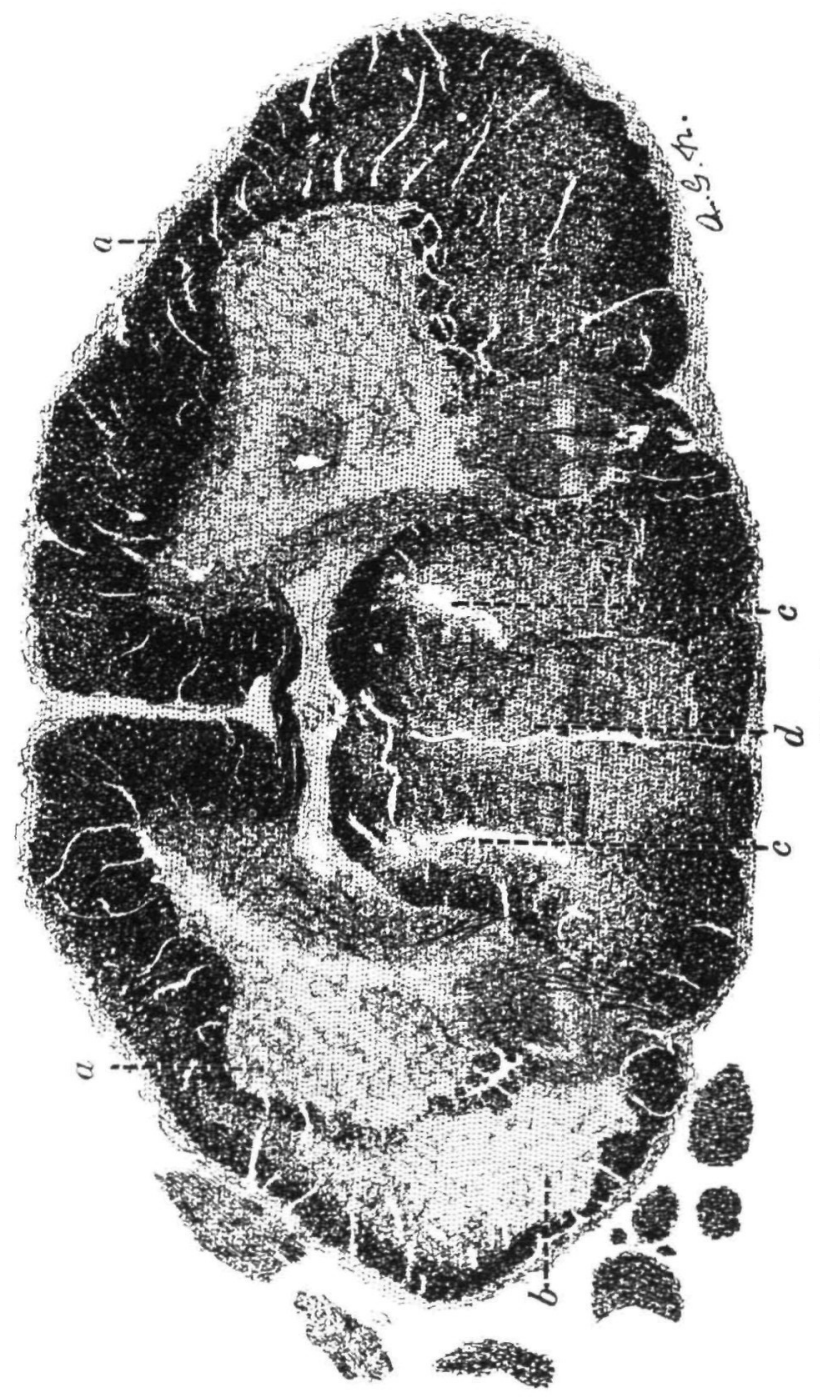

영

홍효 


\section{Comments.}

With reference to the etiology of syringomyelia this case may possibly have some significance. It is true that no cavity had formed in this cord, and the case therefore was not one of true syringomyelia. The seat of the lesion, however, especially about the central canal and in the central grey matter, was practically identical with that of many cases of syringomyelia. So true is this that in looking at these sections the observer feels that he is studying a lesion which only required to advance a step further to become truly a case of cavity in the cord. It would seem that it must have been comparatively easy for this necrotic tissue to have broken down still further and to have been absorbed, thus leaving a cavity of irregular extent and outline in the central region of the cord. If this had occurred in the present case the cavity would have occupied especially the region of the grey commissure extending into the posterior column of the left side, and possibly including the lateral column also. For some reason cavities in the cord, as we know, form most readily in this very region of the grey commissure. The causation of them in most cases is obscure, but the possibility of their being caused by trauma has long been recognised. The interesting question arises, therefore, in this case, whether we are not looking at the result of a trauma which has produced an area of necrosed tissue in this usual place without having advanced to the final step of cavity formation. While this question is somewhat speculative the appearances in this cord are highly suggestive of such a state. Cases are not wanting which show the action of trauma in causing cavities in the central grey matter of the spinal cord. Silcock ${ }^{1}$ reported a case of fracture of the fifth cervical vertebra, with injury to the spinal cord, in a man who had dived into shallow water. In this case the patient lived for some months. At the antopsy a cavity was found lying immediately inside and parallel to the right posterior horn. There was also much

1 Trans. Path. Soc. Lon., vol, xxrix., 1888, p. 18.

VOL. XXI. 
general sclerosis and disorganisation. Among others who have observed trauma as a cause of syringomyelia are Harckin, Strümpell, and Oppenheim, quoted by Brahl.' They have especially noted falls from high places.

According to Hinsdale' the syndrome of syringomyelia is likely to occur suddenly in tranmatic cases, and we may then suspect the existence of hæmatomyelia as a starting point for the cavity formation. Hæmorrhages of the spinal cord, as is well known, affect chiefly the central grey matter. According to this same author, Minor observed the symptoms of syringomyelia in organic lesions of the spinal cord resulting from trauma. While it is true that hæmatomyelia may be the starting point for cavity formation in the cord in most cases due to trauma it does not follow that this condition must be the only one. It is supposable at least that necrosis and softening might occur without hæmorrhage and eventually produce a cavity. In the present case there is no evidence of a hæmorrhagic cyst in the cord. All that can be said is that a necrotic area has been produced in the region most farourable for the production of a cavity, and that, clinically, the case had close resemblance to one of syringoinyelia. Other cases might be quoted from the extensive literature of this subject. ${ }^{8}$

The question of sensory conduction in the spinal cord is still one of some obscurity. So far as one pathological case can throw light upon this subject some inferences may possibly be drawn from the case under consideration. In the first place is to be noted that tactile sensibility was not involved, except in a limited area on the right lower extremity. Why this comparatively limited and isolated area was involved does not appear plain from the microscopic appearances. It is to be observed, however, that this tactile anæsthesia preserved the shape and extent of the ordinary segmental anæsthesia so commonly seen in hysteria. Thus it involved the whole of the foot and leg as high as the knee where it

' "Contribution a l'êtude de la Syringomyélio," Brubl, Paric, 1890.

= "Syringomyelia," Alvarenga Prize Essay, Collego of Physicians of Philadelphia, 1897.

J For an exteusive bibliography, including more than fle liundred references, Hinsdale's Prize Essay, elready quoted, may be consulted. 
was sharply limited by a line drawn horizontal to the long diameter of the limb. In short, it had the appearance of a stocking, or, as when seen in the arm, of a gauntlet. This segmental anæsthesia, not following the distribution of any particular nerve, is hard to explain by an organic lesion. In considering its significance in this case I have been strongly inclined to regard it as an hysterical phenomenon. The patient had some of the mental characteristics of hysteria, and it may well be that this was one of the hysterical stigmata that not uncommonly complicate the picture of organic nervous disease. That it was not due to organic changes in the posterior columns of the cord is rendered probable by the fact that the colamns of Goll at and above the seat of lesion were not seriously involved. Moreover, although slightly implicated, they were equally so on both sides. We know that the sensory fibres from the lower limbs pass upward through the cervical region exclusively in these columns of Goll. Therefore this case presents no reason why total tactile anæsthesia of this peculiar segmental type should be found in only one leg. In the second place, this patient bad the peculiar disassociation symptoms of syringomyelia involving the whole right half of the body. The thermo anæsthesia was not so extensive as the analgesia, since the former involved only the lower limbs and a limited region on the thorax. Finally it is to be observed that this heminnesthesia to pain and temperature was on the side opposite to the main lesion in the cord and to the motor paralysis. Hence in a sense it presents the appearancewithout tactile anæsthesia, however-of a Brown-Sequard peralysis of the spinal cord.

It seems that it is not difficult in the present case to explain the sensory phenomena by the lesions found under the microscope. In the first place, the preservation of tactile sense is perfectly explained by the fact that the posterior columns of the cord were not seriously involved. The parts of these columns most involved were contiguous to the posterior grey commissure, a region in which the endogenous fibres especially of the posterior columns run. The fibres passing in by the posterior roots (exogenous 
fibres) pass up the posterior columns, gradually seeking and entering the columns of Goll. As already said, the columns of Goll are not deeply degenerated at the level of the lesion nor above the level of the lesion. According to Van Gehuchten the probabilities are that these long fibres of the posterior columns, i.e., the exogenous fibres, passing in by the posterior roots, serve for the conduction of tactile sensibility. That is the lesson taught by syringomyelia and also by the present case. These fibres pass up directly into the nuclei graciles and cuniati in the lower part of the medulla oblongata. Here their arborisations are distributed to the neurons of a second order. The microscope in this case does not indicate any marked degeneration of these fibres at or about their point of entrance into these nuclei.

With reference to the thermo anmsthesia and analgesia in this case, I may say that they seem to point unerringly to the conclusion of Van Gehuchten, who says that in all probability pain sense and thermic sense are transmitted through the grey matter by way of cells whose axis cylinders become the fibres which constitute especially the tract of Gowers. These fibres according to the same authority are crossed. In the present case Gowers' tract as well as the direct cerebellar tract was deeply degenerated on the left side from the seat of lesion all the way up. On the right side there was very slight evidence of degeneration in these two tracts. This would put the case in perfect harmony with the anatomical demonstrations of Van Gehachten. The tract of Gowers on the left side above the lesion being degenerated and this tract being composed of axis cylinders arising from cells located in all the segments of the grey matter of the opposite side, it follows of course that the thermo anæsthesia and analgesia would be upon the opposite or right side. This was so in this case. The motor symptoms, i.e., spastic paralysis of the arm and leg with muscular atrophy of the shoulder and upper extremity, were most marked in this case, as always, upon the side of the lesion, i.e., the left side. If this view is found to be confirmed by other cases we must accept a modified view of BrownSequard's paralysis of the spinal cord. Instead of this 
paralysis being characterised by an hemianæsthesia on one side and a hemiplegia on the other we shall have the syndrome constituted as follows:-The motor paralysis and the tactile anæsthesia would be on the side of the lesion, while the anesthesia to pain and temperature would be on the side opposite the lesion. Of course, as in all pathological cases, the present case is open to the objection that the lesion is not sharply defined nor limited strictly to the one side. Yet in looking without prejudice at the sections it must be acknowledged that the lesion is confined very largely to the left side.

It is but fair to say that all anatomists and physiologists do not as yet agree with Van Gehuchten that the tract of Gowers is composed of crossed fibres, or that it is necessarily the pathway for the pain and temperature sense. Yet the present case points strongly to some such conclusion.

According to Gotch ${ }^{1}$ the degenerative changes which follow section of a posterior root are always limited to the side of the lesion and affect only the fibres of the posterior column. This degeneration ceases at the medulla oblongata in the grey matter of the gracile and cuneate nuclei. As the fibres entering the posterior roots divide dichotomously, one branch, already referred to, passing upward, and the other branch looping downward for a short distance to pass into the central grey matter, it follows that in a localised lesion of the posterior columns there might be found some slight descending degeneration in these columns for a short distance below the lesion. There is some evidence of this, but to a very limited extent downward, in this case. Gotch, however, contends that there is no evidence of ascending degeneration on the opposite side of the cord either after a section of a posterior root or after a hemisection. This, however, does not invalidate the claim made here, since the fibres in Gowers' tract and the direct cerebellar tract are endogenous fibres, i.e., take their origin in

1 "Recent Research on the Spinal Cord," by Francis Goteh, M.A., F.R.S., Iiverpool Medical Chi. Journ., riii., 1899, p. 150. 
cells located in the grey matter at the various levels of the cord itself. Impulses from painful and thermal impressions, according to this observer, radiate into the grey matter of the cord, and pass particularly into the lateral columns of the opposite side. This is perfectly in accord with our present case. Hence, to recapitulate briefly, it may be said that tactile impressions pass directly up the posterior columns by way of the exogenous fibres of the same side, while painfal and thermal impressions pass into the grey matter and through the cell bodies of a second order of neurons whose axis cylinders, in a large majority at least, pass across to the opposite side of the cord and up the lateral columns, especially in Gowers' tract. This seems to be the teaching of the case here under review.

In conclusion, I have to express my obligation to Dr. William G. Spiller for his skilful preparation of the sections in this case, and to Miss Anna G. Newbold, of Philadelphir, for her very accurate drawings of the same. 